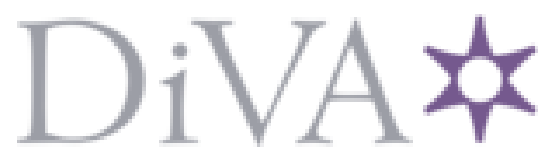

http://www.diva-portal.org

This is the published version of a paper presented at 17th CIRP Design Conference - The Future of Product Development.

Citation for the original published paper:

Ericson, Å., Bergström, M., Johansson, C., Larsson, T. (2007)

On the way to knowledge awareness in early design.

In: Frank-Lothar Krause (ed.), (pp. 607-616). Berlin, Germany: Springer

N.B. When citing this work, cite the original published paper.

Permanent link to this version:

http://urn.kb.se/resolve?urn=urn:nbn:se:bth-11287 


\title{
On the way to knowledge awareness in early design
}

\author{
Å Ericson, M Bergström, C Johansson, T Larsson \\ Division of Computer Aided Design, Luleå University of Technology, \\ Sweden
}

\begin{abstract}
This paper discusses views on decision support in product development to identify factors of relevance when designing computer-based decision support for total offers. Providing services in form of physical artefacts offered as 'functions per unit' is at the heart of total offers. Total offers gain access to possibilities to 'design in' value added characteristics into the physical artefact, e.g., maintenance, monitoring, training, remanufacture. Contemporary computer tools seem to be insufficient to support a $\mathrm{GO} / \mathrm{NO}$ GO decision for total offers. Relevant factors to take into consideration are to support learning and provide the decision makers with insights in a number of plausible 'what-if' scenarios to improve the solution space.
\end{abstract}

\section{Keywords}

Product development, decision-making process, decision support, collaborative engineering

\section{Introduction}

Globalization, increased competition, dynamic and constantly changing business demands are no exception for manufacturing companies in the Swedish industry. In this scenery, the companies have to manage aspects that could be considered as not compatible. For example, customers' want individualized products at the same time as industry has to strive for stan- 
dardization, since cost and time savings are paramount to be viable. The competition is not only about providing high-quality artefacts, but also to provide added value, i.e., a shift towards providing services.

The vision to differentiate physical products by supplying them as services are captured within the idea to provide customers with total offers [1]. The physical artefact, services related to that artefact and company specific knowledge are thought of as elements in the total offer. The total offer is in itself a service, since what is provided is offered as 'functions per unit'. Inherent in a total offer is the intention to provide customers with functions in time and place 'as-needed' in a long term commitment. The sale of functions also gain access to possibilities to upgrade and remanufacture the physical product, as well as provide for 'embedded' maintenance.

However, services are developed differently than physical artefacts. One difference is, "Whereas goods are manufactured, services are performed" [2] (p.65). The customer is present and contributes to the service development process. From a service perspective, the physical artefact is “...just one element in the total, ongoing service offering. For a manufacturer, the physical good is a core element of the service offering, of course, because it is a prerequisite for a successful offering" [3] (p. 9).

Archetypically, the view on products as physical things is embodied in a product development perspective [e.g., 4-6]. Yet, the intentions to provide a total offer affects this view by increased intangibility, for example, in terms of the final result, i.e., functions meeting the customers needs, and in terms of the development process, i.e., to design those functions into physical artefacts. The total offer calls for integrating a diversity of knowledge areas, e.g., business, design and manufacturing, accordingly affecting the product development process in the same way. Besides insisting on coordination and communication in a cross-boundary setting, making the right decisions at the right time is vital in this setting. Contemporary product development is extensively computer aided and the use of Computer Aided Engineering (CAE) tools is established in the industrial context. For example, finite element analysis techniques, as well as knowledge-based systems are used in design activities and, by tradition, bound to geometry modelling. Current tools, focused on hardware parameters, seem to be insufficient to support GO/NO GO decisions for total offers, since they do not provide an overview of a wider set of parameters. It is not apparent which aspects a tool to aid decisions in early design phases of physical artefacts sold in total offers needs to support.

Thus, the purpose in this paper is to describe views on decisions in product development to identify relevant factors to consider when designing computer-based decision support for total offers. 


\section{Data generation}

In general, data for the study presented in this paper has been generated during informal and formal meetings with companies affiliated to a research centre. Data for a functional product development process and a collaborative engineering model have evolved during these meetings. Specifically, data has been generated in a series of workshops, whereas two are in focus for this paper. The participating companies are found within manufacturing industry. There were 15 participants (10 from industry and 5 from academia) in one of the two workshops. 5 companies were represented in that workshop. The intention to focus on computer-based support for total offers evolved during this workshop, as well as the purpose for this study. Notes have been taken during the workshop.

In addition, the second workshop was performed as a 'future workshop' [7], at one of the affiliated companies. The workshop consisted of 8 participants from industry and 4 from academia. The group in a future workshop should include people who will get in direct contact with the tool that is going to be developed. Accordingly, the industry was represented by people from service, business, design and manufacturing departments. The academia was represented by people with different research interests. This made it possible to generate rich data. This workshop has been tape recorded. A future workshop runs in three phases, critique, fantasy and implementation phase. All were performed during the workshop. The critique phase highlights specific problems about the practice 'as-is', and is in focus for this paper.

\section{Approaches to decision-making}

Three approaches to decision-making are put forward by Mintzberg and Westley [8]. Firstly, the 'thinking first' supports planning and works best in, e.g., an established production process, since it is characterised by: a clear issue, reliable data, a structured context, thoughts that can be pinned down and control can be applied. This describes a rational decisionmaking process, where the steps are; (1) define the problem, (2) diagnose its causes, (3) design possible solutions, and (4) decide which is best and implement the choice. Despite being a frequent description, this is an uncommon approach and insufficient to explain decision-making [8].

Secondly, the 'seeing first' supports visioning and works best in, e.g., new product development, when: the combinations of many elements into creative solutions are needed, a key to those solutions is commitment and 
cross-boundary communication is vital. This approach suggests that actions might be driven as much by insights (seeing into) as by what is thought. Experiences and knowledge developed over years is a vital starting position. The seeing first is a base for the following incubation time, "...during which the unconscious mind mulls over the issue. [Then]...there is that flash of illumination" [8] (p.90). This 'eureka moment' often comes when the rational thinking is turned off, e.g. in sleep. So, the actual decision of the choice to go for is more erupting than emerging. However, the verification, e.g., reasoning it all out for elaboration and proof and/or to write it down, takes time [8].

Thirdly, the 'doing first' supports learning and works best when, e.g., companies face disruptive technology. This situation is: novel and confusing, hampered by complicated specification and moved forward by a few simple relationship rules. When it is not possible to see it or think it up, a doing approach is supportive and encourages learning by doing [8].

A traditional approach to decision-making leads actors to view the situation in a binary way, assuming that the world is either certain or uncertain [9]. The former view makes the actors believe that the future situation is possible to predict precisely, and the latter view makes them consider the future as completely unpredictable. Actors that experiences very uncertain environments might not trust their gut-feelings and thus, suffer from decision paralysis. They focus on reengineering, quality management or internal cost-reduction programs instead [9]. To make sound strategic decisions when facing uncertainty, a binary view has to be avoided. The identification of a range of potential outcomes or even a discrete set of scenarios is a simple insight that is extremely powerful to determine which strategy is best [9]. A decisions-making process is intertwined in human analysis processes, thus a work-oriented approach to computational support seems promising [10].

\section{Total Offer Readiness Level - the idea}

"We have something to take into account which we cannot really do today" and an increased intangibility in design decisions were emphasised in the workshops. The discussions rendered up in a need for understanding the maturity level on knowledge to provide total offers. Computational support was recognized as important to engineering activities and an interest for a computer tool to visualise knowledge maturity level emerged. The base for decisions was recognized to support GO/NO GO decisions for total offers. 
The idea for a computer tool, to give insights in the maturity level of knowledge in the company as a whole and to give overview to the possibilities to provide total offers, was named Total Offer Readiness Level (TORL). The discussion was inspired by the technology readiness level used by NASA [11]. The technology readiness level is visualised by a 'thermometer' showing 9 readiness levels, where level 9 correspond to 'flight proven' system, see Figure 1. The overview given by the 'thermometer' was particularly appealing. Though, it was also recognised, by the participants in the workshop, that a total offer aim to encompass more than technical aspects and this is complicating product development, as well as the base for decisions.

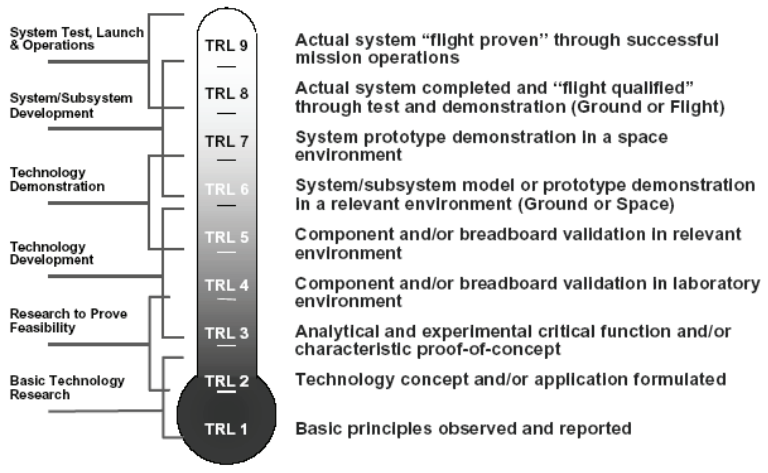

Figure 1: NASA Technology Readiness Level [11].

\section{Problems in decision-making process - as-is}

The informants talked about gathering people with relevant competences and people possessing the ability to influence the decision at higher organisational levels as critical to the decision-making process. It was emphasised that including high level persons in the meetings was necessary to give the decision-making process validity and stability over time. The informants could not describe how they know who had relevant competences, but they mentioned time as a constraint to gather the right people. "A meeting the same day would not be possible since there would probably be a drop off of $90 \%$ ", they said. Two weeks notice was perceived as a necessary time limit to gather most of the relevant people.

Collecting facts from existing computer support were mentioned as easy to access. Existing support were, for example, management tools for project costs and time or process management tools. Tools for process management were described as relating to roles and not to positions in the or- 
ganisation. "How do I know who to talk with when problem occurs in the process?", said one respondent. The possibilities to predict costs for manufacturing over a longer time span was mentioned as causing problems. Many decisions were based on the fact of being an experienced team member, i.e., the task has been done in previous projects. However, the computer support for historical events was found sparse. Despite access to and possibilities to collect facts, the analysing activities were perceived as time consuming. The informants emphasised gut-feeling as important, and as a base for many decisions.

The design process was explained as a continuous dialog with customers about boundaries and possibilities for the physical artefact. The dialogue starts with some kind of document, for example a mechanical drawing or even a very simple form of drawing. From this starting position, the process was described as a long chain of analyses to perform. The procedure to acquire offers from subcontractors in the design phase was found particularly time consuming. One informant said "Here we work very traditionally. To make an inquiry, via our purchase department, we have to have a drawing of some kind. The problem is that documents like that do not exist at this point. Purchase staff has to make guesses sometimes, or describe, as best they can, what they want." He continued, "And, you know, how you put forward your questions affect the answers", and emphasised that the level of details is important. Being focused on an overarching level, small details, e.g., a bolt, can be forgotten, even though utterly important.

The informants started to talk about decisions in the design phase, but realised that "some homework had to be done before". This call attention to that "the right decisions are made long before" the design phase in product development starts.

\section{Identifying relevant factors}

The provision of total offers and the step towards designing physical artefacts to provide 'functions per unit' is likely to affect product development. These changes are in this context captured and addressed in a Functional Product Development (FPD) process. There are elements building up a total offer, e.g., training, maintenance and services, which by some of its characteristics could be perceived as based on experiences, i.e., tacit knowledge. These elements can be handled as separate in product development, for example in aftermarket activities, however in FPD these aspects are thought of as having a holistic effect on the design of the product in early phases. 
The design phases in FPD may need an extended design space to take, for example, life-cycle issues, into account. Early on it is needed to provide a number of business scenarios to be considered, e.g., to develop a physical artefact for transaction, or to develop a physical artefact for a total offer, or to adapt existing artefacts for a long term provision. Hence, it seems like FPD needs to handle ambiguity differently than traditional product development, e.g., to widen the design space and assimilate illstructured goals into the design process. Activities in such a design process can be described as "...creating visions and new ideas, formulating specifications on the basis of a range of competence, and mutual learning and understanding" [12] (p.289).

Viewing product development as occurring on a line of sequences, downstream activities, e.g., product use, monitoring, maintenance and recycling, are needed to be understood as early as possible to influence design decisions. However, in this study it is identified that a design process seems to start earlier than what is thought of. At this stage information about the project are sparse, even tough resolutions has to be made. Initially, gathering people with relevant competences is necessary. The identification of these people is essential to give the decisions validity and stability over time. Furthermore, to enable integration and movement of downstream experiences into early phases, multifunctional design teams seem necessary. In this pre-design decision phase, it seems like computerbased tools needs to support identification of relevant resources and give an overview of when and how they can be used for the upcoming project. A supportive tool might also highlight what resources are lacking, as well as provide aid to identify key people in the organisation when problem occurs in the process. A tool for an overview of the maturity knowledge level should facilitate documentation of these problems to enable new knowledge to emerge based on these experiences.

The novel issues to take into account can be derived from the shift in view and/or from the need to integrate business, design and manufacturing knowledge areas. This integration is fundamental, yet not trivial. The respondents in this study has emphasised that gut-feeling serves as a base for many decisions. In our interpretation this is particularly happening in a pre-design phase when ambiguity about the contents in the project as such is prevalent. So, firstly, the nature of knowledge to integrate from some areas can be understood as tacit, thus not easily identified, captured, justified and formalised into computer applications. Knowledge can also be thought of as in constant change and evolving over time. The task to keep the database up to date might be overwhelming. As a result, there might become a gap between the knowledge maturity level held by people and the knowledge maturity level shown by the computer-based support tool. Thus, a 
situation where people do not trust the result given by the tool can occur. In light of this, learning capabilities could be a relevant factor to the design of the decision tool.

Secondly, people from divergent disciplines have different preferences for how to interact with a computer-based decision tool. This affects the visualisation of the result and the interface. The type of decision tool discussed here is aiming to give an overview of the company's knowledge maturity level. This understanding has to be provided on the right level and in the way that is comprehensible for those working and making decisions on that level. For instance, people from manufacturing functions are more interested in technical details than sales people. Salesmen would like to combine elements into an offer and be able to communicate with customers. In turn, early input from this customer communication is crucial to designers, especially if the offer include new product development. Besides being easy to use and provide for substantial improvements in the design process, the decisions support tool should increase the confidence for those who are using it.

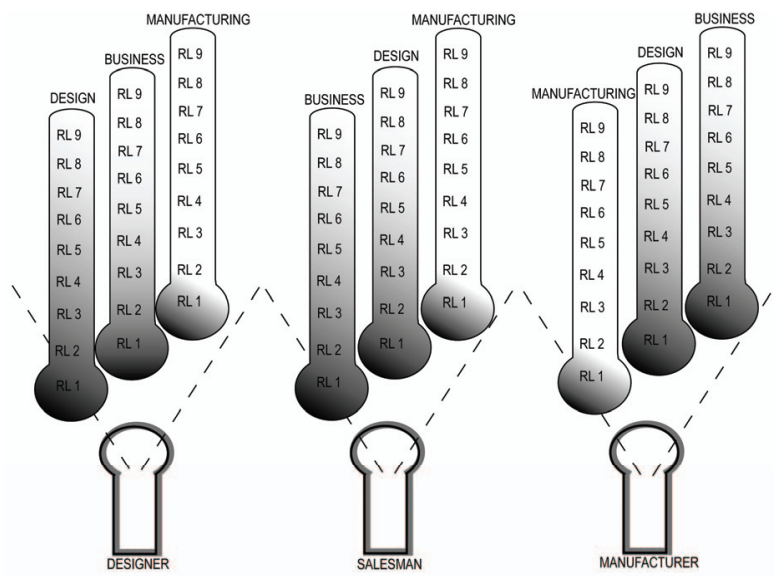

Figure 2: Readiness Level views

Figure 2 is representing the idea, not an application view. The keyholes at the bottom of figure 2 symbolise a 'right' level view. Through these windows a set of related knowledge maturity level visualisations appear. These are in the figure presented as thermometers each showing nine readiness levels (RL 1-9); however in reality the visualisation might differ on different levels and from different views. It is important that the parameters represented are separate, not integrated into one and the same 'thermometer', since it is the relations between these that are of interest 
and provide an overview. For example, in figure 2, in the middle, the salesman can see that the business readiness level is high. This indicates, e.g., that agreement for total offers with customers is under discussion, the company strategy and vision are in line with total offer businesses and customer needs and/or requirements are identified. From this view, it can also be seen that the readiness level for manufacturing is very low. This indicates, e.g., that the company might not have appropriate production equipment, that manufacturing procedures does not exist and has to be developed. And, it can also be seen, that the design readiness level has not yet reached a predefined level. The decision to go for a total offer in this case is not recommendable, since it will not be possible to provide the functions needed by the customer. However, based on this overview, resources to increase the readiness level for design and manufacturing can be put in.

The shift towards service provision could be interpreted as new product development, i.e., the product offered to customers has changed by its nature from primarily a tangible artefact to an intangible service. A 'seeing first' approach [8] enables new ways of thinking and could be aided by a computer-based decision tool which allows visualisation of a number of 'what-if' scenarios and/or a range of potential outcomes. In this way a binary view on the situation as either certain or uncertain [9] can be avoided. A decision tool which provide simulation opportunities support a virtual 'doing first' approach [8], and in turn also provide learning possibilities without causing costly prototyping etc. The use of computer tools can provide swift access to information, yet the analysis of the result is human based.

\section{Conclusion}

The aim in this paper was to discuss views on decisions in product development to identify relevant factors to consider when designing computerbased decision support for total offers. The incitement for the study stem from a need identified in manufacturing industry to understand the knowledge maturity level in the company to be able to provide total offers to customers.

Additional knowledge aspects to take into account in total offers can be understood as tacit, i.e., based on experiences and interpretations. This kind of knowledge is difficult to translate into computer applications, yet it is identified as a relevant factor. Another relevant factor that has been identified is the importance to provide insights in the relations between 
each parameter, thus integration of parameters into one readiness level should be avoided. Decisions for novel and unfamiliar situations could be supported by visualisation and simulation of plausible outcomes and a 'learning by doing' approach. So, to support a GO/NO GO decision for total offers a computer-based decision tool seems to insist on taking learning capabilities as another relevant factor.

In this paper an engineering perspective has been prevalent. We have not considered a business perspective on computer tools to support total offers, still this is of most concern to improve decisions. Studies to further improve the understanding of parameters crucial to total offer readiness level is an ongoing work. For example, a demonstrator capturing some main ideas will be presented and evaluated in a workshop.

\section{References}

1. Alonso-Rasgado, T., Thompson, G., Elfström, B-O. (2004). The design of functional (total care) products, Journal of Engineering Design 15(6), 514540.

2. Berry, L.L. (2002). Relationship Marketing of Services - Perspectives from 1983 and 2000. Journal of Relationship Marketing, 1(1), 59-77.

3. Grönroos, C. (1996). Relationship marketing: strategic and tactical implications. Management Decisions, 34(3), 5-14.

4. Ulrich, K.T. \& Eppinger, S.D. (2000). Product design and development, McGraw-Hill, USA.

5. Roozenburg, N.F.M. \& Eekels, J. (1995). Product design: fundamentals and methods, John Wiley \& Sons, Chichester.

6. Pugh, S. (1991). Total Design - integrated methods for successful product engineering, Addison-Wesley Publishing Company, UK.

7. Kensing, F. \& Madsen, K.H. (1991). Generating Visions: Future Workshops and Metaphorical Design. In Greenbaum, J. \& Kyng, M., Design at work: Cooperative design of computer systems, Lawrence Erlbaum Associates, UK.

8. Mintzberg, H. \& Westley, F. (2001). Decision making: it's not what you think. MIT Sloan Management Review, Spring, 89-93.

9. Courtney, H., Kirkland, J., Viguerie, P. (1997). Strategy under uncertainty, Harvard Business Review, November-December, 67-79.

10. Larsson, T., Larsson, A. \& Karlsson, L. (2001). A modular approach to web based multibody dynamic simulation, CIRP, June 6-8, Stockholm, Sweden.

11. NASA, Technology Readiness Levels: A White Paper, April 6, 1995, URL: www.hq.nasa.gov/office/codeq/trl/trl.pdf, www.hq.nasa.gov/office/codeq / $\mathrm{trl} /$ trlchrt.pdf, Accessed September 25, 2006.

12. Bratteteig, T. \& Stolterman, E. (1997). Design in groups - and All That Jazz. In Kyng, M. \& Mathiassen, L. eds. Computers and design in context. The MIT Press, London, 289-315 